\title{
A comparative study between plating versus titanium elastic nail system in mid-shaft clavicle fracture management
}

\author{
Anil K. Sahu ${ }^{1}$, Bhabani S. Lenka ${ }^{1}$, Abani K. Mishra ${ }^{1}$, Chandan K. Panda ${ }^{1}$, Monali Kar ${ }^{2}$ \\ ${ }^{1}$ Department of Orthopaedics, ${ }^{2}$ Department of Community Medicine, MKCG Medical College, Berhampur, Odisha, \\ India
}

Received: 25 May 2018

Revised: 06 July 2018

Accepted: 09 July 2018

\section{*Correspondence:}

Dr. Chandan K. Panda,

E-mail: pandack88@gmail.com

Copyright: $\odot$ the author(s), publisher and licensee Medip Academy. This is an open-access article distributed under the terms of the Creative Commons Attribution Non-Commercial License, which permits unrestricted non-commercial use, distribution, and reproduction in any medium, provided the original work is properly cited.

\begin{abstract}
Background: Clavicle fracture is one of most common bony injuries. Despite of high frequency, choice of proper treatment is still a challenge. So a comparative randomized study was planned to compare Plating verses TENS for clavicle fractures management.

Methods: Study was conducted in Department of Orthopedics, M.K.C.G Medical College, Berhampur from November 2015 to October 2017.Patients aged from 20-55 years with closed displaced were included in study. Patients were randomized in two groups- One group (25 pateints) treated with TENS and second group (25) with plate. Outcome assessed by pain VAS score, Constant \& Murley score, DASH score, cosmetic result, radiological fracture healing time.

Results: Mean fracture union time in TENS group was $11.4 \pm 2.12$ weeks and in plate group $13.4 \pm 3.46$ weeks (difference was significant $\mathrm{p}=0.016$ ). Mean pain VAS score in TENS group was $2.56 \pm 0.91$ and in plating group $3.12 \pm 0.8(\mathrm{p}=0.023)$. Tens group were cosmetically more satisfied (mean score $4.48 \pm 0.7$ ) than plate group (mean score $3.8 \pm 1.0, \mathrm{p}=0.009$ ). Mean DASH and Constant Shoulder Score in TENS group were 1.87 $\pm 3.4,9.36 \pm 7.04$ and plate group $4.8 \pm 9.0$ and $15.08 \pm 9.4$ respectively. Both were significant $(\mathrm{p}=0.039, \mathrm{p}=0.000)$.

Conclusions: Our study found that patients treated with TENS showed excellent outcome in $84 \%$ cases while $60 \%$ in plating group for displaces mid-shaft clavicle fracture. Patients in TENS group better in terms of Constant \& Murley score and DASH score than treated with plate.
\end{abstract}

Keywords: Clavicle, Randomized trial, Constant and Murley score, Fracture healing

\section{INTRODUCTION}

Clavicle fracture is one of the most common bony injuries. Approximately $2 \%$ to $5 \%$ of all fractures in adults and $10 \%$ to $15 \%$ in children involve the clavicle. ${ }^{1}$ Studies indicate that 29 to 64 per 1, 00000 suffer from a clavicle fracture each year. ${ }^{1,2}$ A weak spot in mid clavicular region accounts for most of fractures. Despite of high frequency, choice of proper treatment is still a challenge for orthopedic surgeon. ${ }^{3}$ In particular it is not clear whether surgery produces better outcomes than non- surgical management. In this scenario, a comparative randomized study was planned to compare Plating verses Titanium Elastic nail System (TENS) for clavicle fractures and compare with respect to incidence of nonunion, shortening, functional outcome, cosmetic aspects and complication. The aim of the study is to analyze the result of TENS management and surgical treatment by plating of displaced midshaft clavicle fracture. It also aimed to compare the functional outcome of displaced fracture of the middle third of clavicle treated with TENS and Plating management. 


\section{METHODS}

The Study was conducted in department of orthopedics, M.K.C.G Medical College, Berhampur. The study period was from November 2015 to October 2017. Patients aged from 20-55 years with closed displaced and isolated fracture of middle third clavicle were included in this study. Those who were not medically fit for surgery, not gave consent, have pathological fracture, with neurovascular deficits, with concomitant injury, with previous fracture clavicle non-union were excluded. Patients coming to the emergency department of orthopedics OPD of the MKCG Medical college, Berhampur within the study period and who qualified the inclusion criteria were randomized in two groups- One group were treated with TENS and second group with plate. Simple randomization was used for patient's allocation to groups. During the study period 78 clavicle fractures, which require surgical treatment were analyzed. Out of which only 50 cases of mid clavicle fracture were included in this study

Patient on admission to emergency unit or OPD was initially resuscitated and stabilized (if required. All the cases were initially investigated with radiograph to asses fracture type and post traumatic clavicular shortening and routine hematological investigation, urine and stool examination, ECG and caridiological check up. Fractures were classified as per AO/OTA Classification. In both cases patients were operated under general anesthesia.

\section{Surgical technique for plating}

After pre operative dose of prophylactic antibiotics, patient was placed in the supine position with a large bump placed between the scapula, allowing injured shoulder girdle to fall posteriorly, helping to restore length and exposed to the clavicle. Reduction was done and a $3.5 \mathrm{~mm}$ Recon plate, LCP, one third tubular plate was contoured with bending for application to the superior surface of the clavicle or antero-inferior surface. In case of long oblique fractures or wedge communated fractures, 1 ag screw were used where possible with care taken to preserve soft tissue attachment. For communated fractures sufficiently long plate with nine or twelve hole was used to bridge the fracture and obtain at least six cortex fixation on each side of fractures.

\section{Surgical technique for TENS}

Patients were placed in supine position. A small incision was made approximately $1 \mathrm{~cm}$ lateral to the sternoclavicular joint. A TEN (Titanium elastic stable intramedullary nial) was inserted (the diameter varied from 2 to $3 \mathrm{~mm}$ depending on the width of the bone). Before introduction, the original curvature of the small and flattened nail tip was straightened slightly to allow better gliding in the small medullary canal. Closed reduction was performed under fluoroscopic control using two percutaneously introduced pointed reduction clamps. The nail was then advanced manually until it was just medial to the acromioclavicular joint. Accurate maneuvering of the nail tip was necessary under fluoroscopic control to avoid penetration of the thin dorsal cortex. After reaching the end point, the fracture was compressed and the nail was cut close to the entry point to minimize soft tissue irritation, at the same time leaving sufficient length behind for easy extraction later on. The fascia and skin were closed in layers.

\section{Postoperative protocol and follow up}

For both the groups Intravenous Antibiotics was given for 3 days and changed to oral antibiotics for 7 days. Operated limb was immobilized in an arm sling. The wound was inspected at $3 \mathrm{rd}$ post operative day and $\mathrm{x}$ ray was taken to study the alignment of fracture fragments. Suture removal was done on 10th postoperative day. Patients were discharged with the arm sling. Rehabilitation of the affected arm was started at the end of 2 weeks. A gentle pendulum exercise of the shoulder in the arm sling was allowed. At 4 to 6 wks gentle range of motion of the shoulder was allowed but abduction in limited to 80 to 90 degree. At 6 to 8 wks active range of motion in all planes were allowed.

All patients were assessed on day 3 , then every 3 weekly, till radiological signs of union, then at 6 month, 9 month, and 12 month after surgery. X-ray was taken for all patients at each follow up for evaluation of fracture healing and implant position.

\section{Outcome assessment}

Radiographic healing was defined as evidence of bridging callus across the fracture site or obliteration of fracture line. Clinically fracture healing is defines as the absence of tenderness with firm palpation over the fracture site, full range of motion and the presence of normal strength of upper extremity. Time to achieve union was recorded. After union, shortening of clavicular length was measured clinically as the linear difference of clavicle lengths from sternal end to acromial end between operated and normal side.

We measured subjective pain with a visual analogue scale (VAS) 1 day before and 3 days months after conservative and surgical management. The VAS ranged from 0-10, $0=$ no pain, to $10=$ worst pain imaginable. The functional outcomes were assessed by Constant and Murley score and DASH score. In Constant and Murley scoring subjective variables are pain and ADL (sleep, work, recreation, sports) which gives a total 35 points. The objective variables are range of motion and strength which give a total of 65 points. Patients were graded as below with a maximum of 100 points. DASH outcome measure is a 30-item, self-report questionnaire designed to measure physical function and symptoms in patients with any or several musculoskeletal disorders of the upper limb. More severely disabled individuals have a 
higher score on a scale of 0 to 100 . Cosmetic results after 6 month is assessed by patient satisfaction score from $1=$ very unsatisfactory to $5=$ very satisfactory. All data were analysed in SPSS version 16. The MannWhitney $U$ test was used to compare the means of variables between two groups as the variables were not normally distributed across two group. $\mathrm{P}$ value below 0.05 was considered to be statistically significant.

Secondary outcome measures include perioperative data like operative time, amount of blood loss and size of the surgical wound; complications such as neurovascular injury, wound infection, nonunion, malunion, implant migration, implant failure, soft tissue irritation, refracture after implant removal and cosmetic outcome with regards to visible deformity, hypertrophic scars and hardware prominence under the skin. Implant removal was not done routinely in our study. It was done as per need and will of the patient after fracture union. The number of days to return to normal activities after implant removal was noted.

\section{RESULTS}

Total 50 patients were studied among whom 25 belonged to TENS group and rest belonged to plating group. The demographic and clinical profiles of patients were depicted in Table 1. There was no significant difference between two groups in respect to these demographic and clinical profiles. The age range of the patient was from 18 to 55 years. The mean age for TENS group was $33.28 \pm 10.73$ and plate group $34.76 \pm 11.87(\mathrm{p}=0.646)$. The injury being a result of trauma was commonly found in male population compared to female in both the groups. Male to female ratio $2.5: 1$. The mode of injury was uniformly distributed in both the groups. $56 \%$ of cases are due to road traffic accident, $16 \%$ cases were due to fall from height and sports activity and due to fall on outstretched hand on $12 \%$ cases. In both the group the dominant side of the patient was more affected (64\%). In respect to type of fracture as per OTA classification, 50\% cases were simple (B1) type and $50 \%$ cases were wedge (B2) type.

In our study 13 patients (52\%) were used locking compression plate, 6 patients $(24 \%)$ recon plate and 6 patients (24\%) semi tubular plate. As per OTA classification for type B1 simple fracture locking compression plates were used in 8 patients $(32 \%)$, recon plates in 3 patients $(12 \%)$ and semi tubular plates in 1 patient (4\%). For type B2 both LCP and STP were used in $20 \%$ cases each. Recon plates were used in 3 patients (12\%) (Table 1).

In our study the fractures in the TENS group were united with an average time of $11.4 \pm 2.12$ weeks and in plate group one case non united but rest cases united with an average time of $13.4 \pm 3.46$ weeks and the difference was significant $(\mathrm{p}=0.016)$.
Table 1: Demographic and clinical profile of study participants $(\mathbf{n}=\mathbf{5 0})$.

\begin{tabular}{|c|c|c|}
\hline Character & $\begin{array}{l}\text { TENS group } \\
(\mathrm{n}=25)\end{array}$ & $\begin{array}{l}\text { Plating group } \\
(\mathrm{n}=25)\end{array}$ \\
\hline Mean age ( in years) & $33.28 \pm 10.7$ & $34.76 \pm 11.8$ \\
\hline \multicolumn{3}{|c|}{ Gender (in number (\%)) } \\
\hline Male & $18(72)$ & $18(72)$ \\
\hline Female & $7(28)$ & $7(28)$ \\
\hline \multicolumn{3}{|c|}{ Mode of injury (in number (\%)) } \\
\hline RTA & $12(48)$ & $16(64)$ \\
\hline $\begin{array}{l}\text { Fall on outstretched } \\
\text { hand }\end{array}$ & $5(20)$ & $1(4)$ \\
\hline Fall from height & $2(8)$ & $6(24)$ \\
\hline Sports & $6(24)$ & $2(8)$ \\
\hline \multicolumn{3}{|c|}{ Side of affection (in number (\%)) } \\
\hline Dominant & $19(76)$ & $13(52)$ \\
\hline Non dominant & $6(24)$ & $12(48)$ \\
\hline \multicolumn{3}{|c|}{ Type of fracture as per OTA (\%) } \\
\hline $\mathrm{B}_{1}$ & $13(52)$ & $12(48)$ \\
\hline $\mathrm{B}_{2}$ & $12(48)$ & $13(52)$ \\
\hline
\end{tabular}

Table 2: Pain as per vas score on day 3 among study participants $(\mathbf{n}=\mathbf{5 0})$.

\begin{tabular}{|lllll|}
\hline $\begin{array}{l}\text { Pain } \\
\text { VAS } \\
\text { score }\end{array}$ & $\begin{array}{l}\text { TENS group } \\
(\mathbf{n = 2 5})\end{array}$ & No. of cases & $\mathbf{\%}$ & $\begin{array}{l}\text { PLATE group } \\
(\mathbf{n = 2 5})\end{array}$ \\
\hline $\mathbf{0}$ & 0 & 0 & 0 & $\mathbf{\text { No. of cases }}$ \\
\hline $\mathbf{1}$ & 2 & 8 & 0 & 0 \\
\hline $\mathbf{2}$ & 11 & 44 & 6 & 0 \\
\hline $\mathbf{3}$ & 9 & 36 & 11 & 24 \\
\hline $\mathbf{4}$ & 2 & 16 & 7 & 44 \\
\hline $\mathbf{5}$ & 1 & 4 & 1 & 28 \\
\hline 6 to $\mathbf{1 0}$ & 0 & 0 & 0 & 4 \\
\hline
\end{tabular}

Table 2 showed the pain VAS score on day 3 among study participants. The mean pain VAS score in TENS group was $2.56 \pm 0.91$ and in plating group was $3.12 \pm 0.83$ and the difference was significant $(\mathrm{p}=0.023)$ (Table 2).

No clavicular shortening was seen in $32 \%$ (8 patients) and less than $5 \mathrm{~mm}$ shortening in $28 \%$ (7 patients) plate cases. 6 patients $(24 \%)$ in plate group shows 6 to $10 \mathrm{~mm}$ shortening. Majority of the patients $(60 \%)$ in TENS group shows no shortening. 8 patients $(32 \%)$ in TENS group shows less than $5 \mathrm{~mm}$ shortening. Mean shortening in TENS group was $1.84 \pm 2.88 \mathrm{~mm}$ and plate group was $4.5 \pm 4.12 \mathrm{~mm}$ and the difference was significant $(\mathrm{p}=0.011)$

Table 3 showed the functional outcome in terms of shortening among study participants. Those having shortening $<15 \mathrm{~mm}$ had excellent result in $100 \%$. $16.7 \%$ had good result and $33.3 \%$ (Table 3 ). 
Table 3: Functional outcome in terms of shortening among study participants $(n=50)$.

\begin{tabular}{|lll|ll|} 
Shortening Excellent & $\begin{array}{l}\text { Good } \\
(\%)\end{array}$ & Fair (\%) & $\begin{array}{l}\text { Poor } \\
(\%)\end{array}$ \\
\hline$<\mathbf{1 5} \mathbf{~ m m}$ & $36(100)$ & $1(16.7)$ & $2(33.3)$ & $0(0)$ \\
\hline$\geq 15 \mathbf{~ m m}$ & $0(0)$ & $5(83.3)$ & $4(66.6)$ & $2(100)$ \\
\hline Total & 36 & 6 & 6 & 2 \\
\hline
\end{tabular}

Table 4: Cosmetic scoring among study participants $(n=50)$.

\begin{tabular}{|lllll|}
\hline $\begin{array}{l}\text { Cosmetic } \\
\text { scoring }\end{array}$ & Tens group $(\mathbf{n}=\mathbf{2 5})$ & \multicolumn{2}{l|}{ Plate group $(\mathbf{n = 2 5})$} \\
\hline $\mathbf{1}$ & 0 & 0 & 0 & 0 \\
\hline $\mathbf{2}$ & 1 & 4 & 3 & 12 \\
\hline $\mathbf{3}$ & 1 & 4 & 6 & 24 \\
\hline $\mathbf{4}$ & 8 & 32 & 9 & 36 \\
\hline $\mathbf{5}$ & 15 & 60 & 7 & 28 \\
\hline
\end{tabular}

In our study, the TENS group were cosmetically more satisfied with mean score $4.48 \pm 0.77$ than the plate group with mean score $3.8 \pm 1.0(p=0.009)$. Table 4 showed cosmetic scoring among study participants (Table 4).

Functional outcome was measured according to Constant Shoulder score and DASH score. In TENS group 21 $(84 \%)$ patients showed excellent result, 2 patients $(8 \%)$ showed good result. But in plate group about 15patients $(60 \%)$ showed excellent result while $16 \%$ cases showed good result.

\section{Comparison of different scores in our study}

In our prospective study mean DASH and Constant shoulder score in TENS group were 1.87 $\pm 3.4,9.36 \pm 7.04$ and plate group $4.8 \pm 9.0$ and $15.08 \pm 9.4$ respectively. $\mathrm{P}$ value for mean DASH score $=0.039$ and $\mathrm{p}$ value for mean constant score $=0.000$ which were significant. Table 5 depicted comparison of different scores among study participants (Table 5).

Table 5: Comparison of different scores among study participants.

\begin{tabular}{|lllll|}
\hline Sl no & $\begin{array}{l}\text { Constant score in tens } \\
\text { group }\end{array}$ & $\begin{array}{l}\text { DASH score in tens } \\
\text { group }\end{array}$ & $\begin{array}{l}\text { Constant score in } \\
\text { plate group }\end{array}$ & $\begin{array}{l}\text { DASH score in plate } \\
\text { group }\end{array}$ \\
\hline $\mathbf{1}$ & 10 & 4.5 & 10 & 1 \\
\hline $\mathbf{2}$ & 10 & 3.0 & 10 & 1.8 \\
\hline $\mathbf{3}$ & 9 & 13 & 10 & 1.3 \\
\hline $\mathbf{4}$ & 6 & 3.8 & 10 & 1.4 \\
\hline $\mathbf{5}$ & 7 & 2.7 & 10 & 2.0 \\
\hline $\mathbf{6}$ & 5 & 3.4 & 9 & 1.10 \\
\hline $\mathbf{7}$ & 9 & 3.9 & 8 & 1.02 .5 \\
\hline $\mathbf{8}$ & 10 & 37.4 & 10 & 3.8 .8 \\
\hline $\mathbf{9}$ & 10 & 5.0 & 10 & 1.5 \\
\hline $\mathbf{1 0}$ & 6 & 2.2 & 10 & 1.2 \\
\hline $\mathbf{1 1}$ & 8 & 1.9 & 10 & 0.8 \\
\hline $\mathbf{1 2}$ & 6 & 2.4 & 10 & 00 \\
\hline $\mathbf{1 3}$ & 8 & 3.4 & 8 & 00 \\
\hline $\mathbf{1 4}$ & 7 & 2.0 & 9 & 10.5 \\
\hline $\mathbf{1 5}$ & 6 & 3.8 & 10 & 25 \\
\hline $\mathbf{1 6}$ & 5 & 4.7 & 12 & 40 \\
\hline $\mathbf{1 7}$ & 4 & 15.9 & 14 & 1.0 \\
\hline $\mathbf{1 8}$ & 6 & 14.6 & 18 & 2.5 \\
\hline $\mathbf{1 9}$ & 3 & 3.1 & 19 & 0.8 \\
\hline $\mathbf{2 0}$ & 6 & 3.9 & 26 & 1 \\
\hline $\mathbf{2 1}$ & 5 & 2.2 & 27 & 8 \\
\hline $\mathbf{2 2}$ & 16 & 2.9 & 25 & 8 \\
\hline $\mathbf{2 3}$ & 13 & 3.4 & 23 & 00 \\
\hline $\mathbf{2 4}$ & 22 & 10.8 & 28 & 4.2 \\
\hline $\mathbf{2 5}$ & 37 & 2.8 & 49 & 4.2 \\
\hline & & & & \\
\hline
\end{tabular}

In TENS group we found the complications are delayed union in $4 \%$, infection in $4 \%$. In TENS group, majority of the cases $(68 \%)$ had radiological union within 9-12 weeks \& 7 patients $(28 \%)$ had union at $13-15$ weeks. But plate group majority $(60 \%)$ had it in about $9-12$ weeks with mean union time 13.4 weeks with $4 \%$ having non union, $4 \%$ having delayed union and $4 \%$ having mal-union. In addition to it in plate group, hypertrophic scar was found in $12 \%$ cases, plates loosening due to infection in $8 \%$ cases, $8 \%$ patient showed superficial infection and $4 \%$ 
showed re-fracture. TENS group is better in terms of infection, plate loosening, hypertrophic scar and plate prominence, refracture or neurovascular injury as no such complication was found in TENS group.

\section{DISCUSSION}

The clavicle has an integral role not only in the mechanics of the pectoral girdle but also in the function of upper extremity. Clavicle fractures accounts for approximately $2.6 \%$ of all fracture. ${ }^{1,4-7}$ The majority of clavicle fractures (80-85\%) occur in midshaft of bone where the typical compressive forces applied to the shoulder and narrow cross section of the bone combine and result in the bony failure. ${ }^{3,4,8,9}$ Most of the $(97 \%)$ in this group are mild to moderate displaced and can be treated conservatively. However $3 \%$ of middle third clavicle fractures are completely displaced and shortened. This small group of fractures accounts for $90 \%$ of nonunion of the middle third fractures and therefore may warrant early open reduction and internal fixation. Our study was done to compare the rate of union and functional outcome in displaced middle third clavicle fractures by surgical management using TENS vs plating. This study was conducted in the post graduate department of Orthopaedics, M.K.C.G Medical college, Berhampur from November 2015 to October 2017.

In our study mean age of the patients with displaced mid shaft clavicle fracture in TENS group was 33.28 years and in plate group was 34.76 years. Nordquist et al. reported mean age to be 29.3 years and the incidence appears to decrease significantly after second decade of life. ${ }^{1}$ Study conducted by Bostman et al Showed the average age was 33.4 years. ${ }^{10}$ Nordquist et al. and Bostman et al in their studies found that males outnumber the females. Our study also found $72 \%$ of participants were males. $^{1,10}$

Plate osteosynthesis is the gold standard method for surgical treatment of clavicular fracture. Plate fixation can provide immediate rigid fixation. The convenient 3.5 mm DCP, RP, STP are usually used routinely. New type such as LCP, Precounter LCP, LC-DCP have been developed to decrease the hard wire irritation, and implant failure. In our study we use $3.5 \mathrm{~mm} \mathrm{LCP}$ in $52 \%$ patients and RP in $24 \%$ and STP in $24 \%$ cases. According to our study the mean radiological union time in TENS group was $11.4 \pm 2.12$ weeks and plate group 13.4 \pm 3.46 weeks. TENS was found to be superior in terms of radiological union for the fracture of middle third of the clavicle than plate fixation as the mean difference was significant. In our study we use Titanium elastic nail in TENS group and $3.5 \mathrm{~mm}$ LCP, RP or STP in plate group. In TENS group we found the complications are delayed union (4\%), infection (4\%). In TENS group, majority of the cases (68\%) had radiological union within 9-12 weeks and 7 patients (28\%) had union at $13-15$ weeks. But plate group majority of the plates $60 \%$ (15 patients) had it in about 912 weeks with mean union time 13.4 weeks with $1(4 \%)$ having non union, 1 (4\%) having delayed union and 1 (4\%) having mal-union. In addition to it in plate group, hypertrophic scar was found in $12 \%$ cases, plates loosening due to infection in $8 \%$ cases, $8 \%$ patient showed superficial infection and $4 \%$ showed re-fracture. TENS group is better in terms of infection, plate loosening, hypertrophic scar and plate prominence, refracture or neurovascular injury as no such complication was found in TENS group.

Although plating of the clavicle spares the original fracture site it rarely involves fixation along its entire length. Refracture secondary to additional trauma either medial and lateral to original occurs and reported at a rate between $1 \%$ to $2 \%$ by Mckee et al. ${ }^{9}$ Poigenfurst et al reported in 4 patients out of 122 patients refracture occurs. ${ }^{11}$ Refracture needs revision surgery. Our study shows refracture rate $4 \%$ (one patient) in plate group.

In our study mean constant score in TENS group was $9.36 \pm 7.04$ and plate group 15.08 \pm 9.0 . Patients treated by plating showed excellent outcome in $60 \%$ cases while $84 \%$ in TENS group. The mean DASH score was found to be $1.87 \pm 3.4$ in TENS group and $4.8 \pm 5.9$ in plate group. Patients treated with TENS were found to be better in terms of CONSTANT and DASH score than treated with plate. TENS group had significantly higher mean cosmetic score than the plate group $(p=0.039)$. Saha et al reported that patients treated by plating of displaced mid shaft clavicle fracture, the mean constant score was 95.2 and mean DASH score was $5 .{ }^{12}$ Mckee et al found that mean constant score in CONS group 91.6 \pm 14.1 and in plate group $97 \pm 4.5$ and mean Dash score $4.1 \pm 7.0$ and $11.49 \pm 7$ respectively. ${ }^{13}$

\section{CONCLUSION}

Our study found that patients treated by plating showed excellent outcome in $60 \%$ cases while $84 \%$ in TENS group. Patients treated with TENS were found to be better in terms of Constant and DASH score than treated with plate. TENS group had significantly higher mean cosmetic score than the plate group. So in the management of acute displaced midshaft clavicular fractures, TENS is superior to plating for management of clavicular fracture. Surgery with TENS results good functional outcome compared with surgical plating treatment.

\section{ACKNOWLEDGEMENTS}

The authors express their gratitude towards all study participants for their valuable time. Authors would like to extend their gratitude to the staffs of the department of Orthopaedics, MKCG Medical College, Berhampur for their contributions and technical supports.

\author{
Funding: No funding sources \\ Conflict of interest: None declared \\ Ethical approval: The study was approved by the \\ institutional ethics committee
}




\section{REFERENCES}

1. Nordqvist A, Petersson C. The incidence of fractures of the clavicle. Clin Orthop. 1994;3:12732.

2. Robinson $\mathrm{C}$ M. Fractures of the clavicle in the adult. J Bone Joint Surg Br. 1998;80:476-84.

3. Rowe CR. An atlas of anatomy and treatment of midclavicular fractures. Clin Orthop. 1968;58:2942.

4. Neer CS. Nonunion of the clavicle. JAMA. 1960;17:1006-11.

5. Lenza M, Belloti JC, Andriolo RB, Gomes Dos Santos JB, Faloppa F. Conservative interventions for treating middle third clavicle fractures in adolescents and adults. Cochrane Database of Systematic Rev. 2009;2:CD007121.

6. Neviaser JS. The treatment of fractures of the clavicle. Surg Clin North Am. 1963;43:1555-63.

7. Nowak J, Holgersson M, Larsson S. Can we predict long-term sequelae after fractures of the clavicle based on initial findings? A prospective study with 9 to 10 years follow-up. J Shoulder Elbow Surg 2004;13:479-86.

8. Allman FL. Fractures and ligamentous injuries of the clavicle and its articulation. J Bone Joint Surg Am. 1967;49:774-84.
9. McKee MD. Optimal treatment of displaced midshaft fractures of the clavicle. Philidelphia, Saunders. 2009; 1:126-32.

10. Bostman O, Manninen M, Pihlajamaki $H$. Complications of plate fixation in fresh displaced midclavicular fractures. J Trauma. 1997;43:778-83.

11. Poigenfurst J, Reiler T, Fischer W. Plating of fresh clavicular fractures,Experience with 60 operations. Unfallchirurgie. 1988;14:26-37.

12. Saha P, Datta P, Ayan S, Garg AK, Bandyopadhyay U, Kundu S. A comparative studyPlate versus titanium elastic nail in treatment of displaced midshaft clavicle fractures. Indian $\mathbf{J}$ Orthop. 2014;48(6):587-93.

13. McKee MD, Wild LM, Schemitsch EH. Midshaft malunion of the clavicle.Surgical technique. J Bone Joint Surg Am. 2004;86:37-44.

Cite this article as: Sahu AK, Lenka BS, Mishra AK, Panda CK, Kar M. A comparative study between plating versus titanium elastic nail system in mid-shaft clavicle fracture management. Int J Res Orthop 2018;4:741-6. 